\title{
Using Boyer to create a culture of scholarship: Outcomes from a faculty development program
}

\author{
Maryann Forbes, Jane H. White \\ School of Nursing, Adelphi University, Garden City, NY, USA
}

Correspondence: Maryann Forbes. Address: School of Nursing, Adelphi University, One South Ave, Alumnae Hall Room 205, Garden City, NY 11530. Telephone: 516-877-3597. Email: forbes@adelphi.edu

Received: December 8, 2011

Accepted: February 12, $2012 \quad$ Published: August 1, 2012

DOI : $10.5430 /$ jnep.v2n3p54

URL: http://dx.doi.org/10.5430/jnep.v2n3p54

\section{Abstract}

Background: The current nursing faculty shortage has created an urgent need to retain and mentor novice faculty members. Programs to foster faculty development related to scholarship should be part of a school's overall strategic plan.

Methods: This article presents a description of a faculty development program with outcomes regarding scholarship for a five year period. The Boyer model of scholarship was used as a framework to assess resources and also served as a guide for program development. The program was tailored to faculty needs and targeted specific aspects of Boyer's domains; strategies were developed which promoted faculty growth in these areas. Specific activities were planned and implemented to accomplish the overall outcome of increasing faculty scholarship and create a research culture in the school.

Results: The scholarship of discovery was a major area identified for faculty growth. The program goal of increasing faculty scholarship was achieved by an increase in the number of presentations, publications and funded projects for the faculty in the school over a five year period.

Conclusions: Using the Boyer model as a framework assisted faculty in achieving a more positive view of their scholarship, facilitated preparation of meaningful dossiers for promotion and tenure decisions, and contributed to knowledge development in the discipline.

\section{Key words}

Faculty, Scholarship, Boyer, Research culture, Tenure

\section{I ntroduction}

With the current faculty shortage in the US, many schools of nursing struggle to fill positions and ensure that faculty who are hired will stay. At our university, less than $15 \%$ of current faculty have tenure and all earned tenure more than 30 years ago. Like many schools of nursing, the majority of faculty on tenure track are junior and many are "newly minted" doctorates. In this context, faculty development becomes an essential strategy to promote positive tenure decisions and ensure a stable faculty. Students also benefit from faculty who are able to combine their research and teaching which strengthens both dimensions of scholarship. 
Promotion and tenure criteria generally require that all faculty in the university be held to the same criteria related to scholarship. As members of a professional practice discipline, nursing faculty can be at risk, in particular at those universities which use traditional research as the main criterion for such decisions. In addition, many growing universities and colleges are expanding their faculty ranks and research status, and criteria for promotion and tenure may have recently become more difficult to achieve ${ }^{[1]}$. Therefore, faculty development which assists the novice nursing faculty member with a program of scholarship is essential to retention and must be part of a school's overall strategic plan.

A broader vision of the faculty role has been proposed by Boyer (1990), who expanded the definition of traditional scholarship to encompass four other dimensions - discovery, integration, application and teaching ${ }^{[2]}$. Creating a "culture of scholarship" in a school which focuses on all dimensions is particularly important for a professional discipline such as nursing ${ }^{[3]}$.

This article describes a comprehensive faculty development program initiated because of the need to retain novice nursing faculty, most with newly earned doctorates. The Boyer model was used as an overall framework to provide structure for program activities and evaluate outcomes ${ }^{[2]}$. Five years of outcome data are provided and linked to the program goals related to the discovery domain of an increase in faculty scholarship. Benefits and limitations of the scholarship program are discussed in comparison to the reported literature. Conclusions are drawn related to the need in nursing for specific and strategic development programs which utilize the Boyer Model as a framework.

\section{Review of the literature}

The literature reviewed focused on three main areas of faculty development: the rationale for and importance of faculty development, the types of programs developed and offered, and challenges or barriers to faculty development initiatives related to scholarship.

\subsection{Rationale and importance of faculty development programs}

The nursing faculty shortage and its influence on today's need to retain current faculty has been well documented ${ }^{[4,5]}$. The National League for Nursing's position paper on faculty mentoring cites retirement as well as faculty exodus for higher paying positions as significant contributing factors ${ }^{[6]}$. Nursing faculty have cited such factors as role ambiguity, isolation, lack of support and leadership as well as inadequate time for scholarship as contributing to job stress, lack of satisfaction, and poor retention ${ }^{[7-10]}$. Novice faculty members, in particular, may experience role ambiguity because they are unclear about their roles as well as the emphasis they should place on each component of their role. The mystery that may surround requirements/criteria for evaluation, promotion and tenure contributes to this difficulty ${ }^{[11-13]}$. Feelings of isolation and "culture shock" experienced by new faculty have been factors cited in the literature that highlight the need for improvements in existing faculty development programs and orientations ${ }^{[6,13,14]}$. Recent work by Benner and colleagues on educating nurses, a "call for radical transformation" has further underscored the need for retention and development efforts to assist nursing faculty ${ }^{[7]}$. The National League for Nursing has developed a Tool Kit for faculty mentoring aimed not only at novice faculty but for those in other phases of their career as well ${ }^{[15]}$.

\subsection{Focus and types of faculty development programs}

Some development programs reported in the literature have focused on enhancing the teaching role, in particular clinical teaching ${ }^{[16,17]}$. Other reports have outlined ways to support teaching such as team teaching or assistance with teaching technology. Faculty development has been conceptualized as a role transition; many novice faculty struggle with the move from a clinical position to academe and have difficulty with socialization into the varied aspects of the faculty role ${ }^{[18,19]}$. In the last several years, the literature has highlighted the need for strategies to develop the traditional researcher role or to increase scholarship in this role ${ }^{[20,21]}$. However, in non-research intensive universities, faculty scholarship may not rest 
entirely on traditional research efforts; therefore it has been suggested that faculty development programs in these settings must take on a broader focus ${ }^{[14,19]}$.

The most often cited strategy for faculty development was the initiation of mentoring programs. There were many types of mentors and models for mentoring described in the literature. Some programs utilize the model of senior faculty who mentor junior members ${ }^{[8,22]}$, or research faculty who mentor "newly minted" doctorally-prepared faculty in developing a program of research ${ }^{[12,20]}$. The use of a consultant ${ }^{[23]}$, and peer-mentoring as well as group mentoring have been proposed $^{[24]}$. Characteristics of effective mentors and the mentoring relationship have also been reported and have been outlined specifically by the NLN ${ }^{[6,20,25]}$.

Mentoring programs described have a wide range of purposes such as socialization of faculty ${ }^{[25]}$; orienting novice faculty ${ }^{[26]}$; assisting with aspects of teaching such as test preparation, grading and use of technology ${ }^{[8]}$; developing research skills and programs of research ${ }^{[20]}$; and overall role adjustment and preparation ${ }^{[18]}$. Noteworthy, often missing from these published experiences and descriptions was an evaluation of the effectiveness of such mentoring programs with measurable outcomes.

\subsection{Barriers and challenges for faculty development programs}

Barriers and challenges to establishing successful faculty development programs were identified as insufficient amounts of time, in particular release time to pursue scholarship, perceptions of lack of administrative support or leadership, too few of the necessary resources and/or opportunities for program success, and tension between existing and new faculty ${ }^{[27]}$. Heavy undergraduate clinical teaching loads can be especially time consuming for new teachers and may serve as a barrier to completing scholarship or research ${ }^{[10]}$. Other barriers described specifically for clinical academics were the limited time available for research given necessary clinical activities and a lack of assistance in writing for publication ${ }^{[28]}$.

\section{Program framework: the Boyer model}

In light of the well documented importance of faculty development, we designed a comprehensive faculty development program (FDP) which had a broader focus than has previously been described in the literature and was structured around the Boyer Model of Scholarship. This broadened paradigm of scholarship is recognized by our university and many others as the foundation for assessing faculty scholarship. When used as a guide for tenure and promotion evaluation, the Boyer model allows for a review of faculty scholarship which is not discipline specific, but rather aims for consistency across all disciplines.

In the classic work Scholarship Reconsidered: Priorities for the Professoriate, Boyer (1990) reflected on the focus of faculty roles throughout the history of American education and proposed a model which offered an alternate paradigm for defining faculty scholarship ${ }^{[2]}$. This work stimulated extensive scholarly discussion and writing over the past two decades and was adopted by many universities as a model for tenure and promotion evaluation. Fitzpatrick and McCarthy reported that this comprehensive view of scholarship has been lauded as the most appropriate for professional disciplines such as nursing even though universities may overly emphasize research at the expense of integration, application and teaching dimensions ${ }^{[3]}$.

Boyer proposed a structure which contains four distinct yet interlocking parts; these include the scholarship of discovery, integration, application and teaching. The domain of discovery contributes to the intellectual climate of the university and consists of scientific inquiry which either generates new knowledge or validates existing knowledge. Scholarly research is at the heart of academic life and has most recently been the focus of recognition and rewards for faculty in academia. In proposing the scholarship of integration, Boyer suggested that there is a need to go beyond the isolated facts obtained from research and make connections across disciplines. The scholarship of application entails relating theory and research to the realities of practice and "real life" situations. Service activities, a form of applied scholarship, are a key component of 
many faculty roles; they can be considered scholarship only if they are tied directly to a specialized field of knowledge. Boyer viewed the domain of teaching as the "heart of the scholarly endeavor". Although teaching often is the primary reason many faculty come to academia, in many universities there is limited recognition of teaching excellence, and therefore it has often been relegated to a lesser role.

The teaching domain of scholarship has stimulated much discussion and controversy in the two decades since Boyer's work was first published. Much has been written about the distinction between the concepts of scholarly teaching and the scholarship of teaching ${ }^{[29-31]}$. Scholarly teaching is based on practice wisdom and refers to teaching excellence and application of educational principles to the practice of teaching ${ }^{[29]}$. The scholarship of teaching goes beyond teaching excellence and involves systematic evaluation of teaching and learning; teaching must be public, peer reviewed and critiqued, and exchanged with other members of our profession.

In addition to Boyer, the work of Pratt, Margaritis and Coy related to developing a research culture in a university was also incorporated into the program ${ }^{[32]}$. They described careful planning of the program as being essential to success; important aspects were providing clear guidelines, outcomes, and determining necessary resources. They viewed a successful program as including clear goals for coordination, appropriate rewards, frequent communication and adequate human resources. Changing beliefs in a system is inherent in creating a "culture".

The structure provided from the Boyer Model, together with a clear vision of our university mission and an understanding of the criteria for assessing faculty scholarship at our university were instrumental in guiding the creation of our faculty development program. We believed that faculty beliefs regarding traditional research as the only valued form of scholarship for promotion and tenure could be re-conceptualized by fostering a culture of supporting all domains of scholarly work.

\section{Program overview and goals}

The School of Nursing is one of six schools in this private, growing mid-sized Carnegie Doctoral Research designated university in the mid-Atlantic. The mission of the university is to provide quality undergraduate and graduate education and to offer professional preparation of the first rank in arts, education, business, clinical psychology, social work, nursing and other health sciences (www.adelphi.edu/mission).

All faculty in the university regardless of discipline are subject to the same criteria for promotion and tenure, with the university using the Boyer model as a guide for evaluation. This model is supported by the faculty and university administration/ Provost. Different schools (units) can define forms of scholarship. For example, what constitutes forms of scholarly work for those teaching in music and art is quite different from those in other schools. Teaching is evaluated using student and faculty peer evaluations. Dossiers for tenure application are, like most universities, subjected to external review by at least six national "peers". The university operates under the auspices of the American Association of University Professors (AAUP) that represents all faculty members including adjuncts. The Collective Bargaining Agreement and the University's By-Laws and Operating Procedures both outline guidelines for promotion and tenure and are in synchrony.

The School of Nursing during this period had approximately 35 doctorally- prepared faculty members on a tenure track; at least $85 \%$ of these were untenured. The large number of untenured faculty was due to recent retirements and an expansion of undergraduate enrollment with resulting new faculty lines. The school has an undergraduate, RN to BS and four specialty masters programs and was in the process of launching a PhD program at the initiation of our program, which was a significant impetus for faculty development especially related to the domain of discovery. 
Two major administrative initiatives in the school of nursing were essential to the establishment of a successful development program. Foremost, and prior to the assessment phase, the Dean created a position for an Associate Dean for Research. The new Associate Dean then created a strategic plan that included development goals in order to address faculty scholarship and ultimately tenure. Careful planning, clear goals and coordination as outlined by Pratt et al. were central to the program's development ${ }^{[32]}$.

Several key factors identified in the literature guided the efforts towards program development such as the importance of establishing and nurturing a research climate in the school, the need for congruence with university and school mission and goals, and the benefits of initiating a mentoring program. It was also evident that a preliminary assessment of each individual faculty member's objectives and needs as well as the existing faculty, school, university and community resources was required. An essential aspect of the program was the incorporation of a measure of its success in the form of outcome data on faculty productivity such as publications and presentations.

The interrelated goals of the program were to provide a Faculty Development Program (FDP) that would:

- Increase faculty scholarship in targeted areas of Boyer's model

- Create and maintain a robust research environment in the school

- Increase the visibility of the school

\section{Assessment of existing resources and faculty needs}

An assessment of existing resources to support each domain of faculty scholarship as described by Boyer (1990) was undertaken ${ }^{[2]}$. These existing resources were then used as the foundation for developing strategies to accomplish the program's goals.

\subsection{Faculty needs assessment}

The Associate Dean for Research met with most faculty to discuss their individual development objectives and their scholarship contributions to date.

Importantly it was an opportunity to plan for tenure and next steps, especially for the novice faculty member. During these initial assessment meetings to determine scholarship contributions to date, all faculty were enthusiastic about scholarship and contributions they could make to not only their own portfolios but to the discipline.

In assessing the faculty, most novice faculty had some experience with teaching (usually in the adjunct role). To promote excellence in teaching, a peer review evaluation process was well established in the school and assisted with one to one observation and feedback regarding teaching. However, the scholarship of teaching was an identified area for potential growth, with few faculty producing peer reviewed scholarship related to their teaching. In assessing resources related to the scholarship of application, Boyer's model identifies that certain types of service, if tied to a faculty member's disciplinary expertise and shared with others outside the university, are forms of scholarship. There were many opportunities for service at the university such as committee membership in the school and university. However some of these committee memberships were not well-aligned with faculty areas of expertise and overall goals for tenure/ scholarship. Resources identified for the scholarship of integration were strong interdisciplinary relationships with the other schools in the university, with the potential for research collaboration.

Based on the assessment, the area most in need of development for this faculty was the domain of discovery. Faculty publications, research grants and national presentations were limited and were an area for growth. Many faculty members had just received their doctoral degrees and had not as yet published their dissertations. Thus, the discovery domain became a major focus of the program. Table 1 describes some of the areas assessed and available resources related 
specifically to the domain of discovery. The faculty and the school were committed to contributing to knowledge for the discipline and with a new $\mathrm{PhD}$ program recognized the importance of this in preparing future scholars and researchers.

Areas for potential research/ scholarship were discussed with individual faculty members and built on existing strengths. For the most part, novice faculty expressed an interest in beginning by expanding the work they had completed during their doctoral studies. A large number of our faculty members had completed doctoral work within the last 4 years. Some of the topics were educationally focused especially for those faculty obtaining education doctorates. Those with nursing doctorates focused on clinical problems for investigation. However, some faculty with years of teaching experience viewed nursing education as an area for a program of research; they chose to investigate such topics as the effect of simulation on student learning. Because interdisciplinary research is a focus on campus, some nursing faculty members looked toward other schools on campus for potential collaboration.

\subsection{School assessment/ resources}

The School of Nursing's resources related to scholarship included strong administrative support, university funds that supported Graduate Student Research Assistantships and seed monies for pilot studies, school of nursing funding for conference attendance for paper presentations, and a school of nursing endowment for invited lectures for faculty development. The creation and subsequent hiring of an Associate Dean for Research was also a strength related to discovery. Missing from the school was any type of mentoring program that might assist faculty individually to reach tenure goals. The school lacked a significant research "culture" with organized research activities; especially disconcerting in light of the present planning and launching of a new $\mathrm{PhD}$ program.

\subsection{University assessment/ resources}

The University provided numerous opportunities and support for faculty advancement in the teaching and discovery domains. Meetings and luncheons for untenured faculty were held monthly to discuss issues related to faculty scholarship and tenure applications. To support discovery there were competitive research awards available for pilot studies and significant growth in library resources and research-oriented data bases. Other doctoral programs on campus existed with faculty engaged in research for potential collaboration. A well-established IRB provided guidance on issues related to ethical conduct of research. Teaching support was provided in the form of a Faculty Center for Professional Excellence that provided workshops and individual assistance for enhanced teaching strategies and the use of classroom technology. To further enhance the teaching domain, there were a number of committees in place that presented programs on innovative teaching methods; one committee reviews academic programs and courses for rigor in content and teaching methods.

\subsection{Community assessment/ resources}

Clinical sites in the community were assessed to determine both the feasibility of and interest in research collaboration; we noted that our faculty were members of a number of existing committees and this might be a vehicle for establishing collaborative research relationships. These committees were responsible for planning research events and providing assistance to clinical agencies with their research.

\subsection{Assessment findings}

Not surprisingly, and supported by the literature, the assessment revealed that the Boyer domain of discovery was the area in which faculty needed the most support and assistance in making use of available resources. It also indicated a need for additional strategies to support faculty in this area. For example, while there were significant resources in the form of "seed" monies for funding, assistance for developing and writing research proposals to obtain funding was needed. Assistance was also needed in the form of encouragement and support to publish work that had been completed. For example, several faculty had completed dissertations but had not published them because they needed assistance in 
converting a large manuscript into a publishable article. In addition, while there were Graduate Assistants available, strategies for engaging the assistants in faculty research projects needed to be developed.

With such a large number of novice faculty, the need for a more formalized mentoring program was also apparent. Therefore, one senior faculty member developed a survey (The Mentoring Needs Survey) to better understand specific faculty needs regarding mentoring and to match protégés with mentors. Individual mentoring needs were considered for teaching, service and research; faculty were also queried to determine in which areas they could serve as a mentor. Most novice faculty identified the domain of discovery as the most needed development area.

The collected assessment data on existing resources, information obtained from the mentoring surveys, and individual faculty meetings with the Research Dean were used to plan activities to accomplish the goals of the program.

\section{Planning and implementing the faculty development program}

Planning for the program involved developing activities to support faculty growth in each domain of scholarship as outlined by Boyer. Determining the appropriate emphasis on areas to target was accomplished by taking into account several factors: the school/ university mission and goals, the relative existing strengths/ resources of the school as determined by the needs assessment, as well as specific research/discovery assistance needed by each faculty member.

\subsection{Strategies to foster the scholarship of discovery}

Faculty development in the area of discovery focused on several initiatives: establishing a research council, implementing a mentoring program, ensuring faculty committee membership on university research committees, developing funding sources outside the school, working closely with the Associate Dean for Research, and rewarding productivity and dissemination. These are outlined in Table 2. The faculty were also assisted with resources already in place such as graduate assistants and how to use and evaluate them (see Table 1). A mechanism for faculty reporting in order to track all scholarly work for outcome measurement as well as school visibility was centralized by the Office of the Associate Dean for Research. In keeping with Boyer's vision, we considered peer reviewed presentations, both podium and poster, as important for visibility of the school; these often led to manuscript development and an opportunity for networking for possible research collaborations.

Table 1. Available Resources for Faculty Development within Boyer’s Discovery Domain

\begin{tabular}{ll}
\hline \multicolumn{1}{c}{ FACULTY } & \multicolumn{1}{c}{ UNIVERSITY } \\
\hline $\begin{array}{l}\text { 95\% doctorally- prepared on tenure track; and 2 PhD } \\
\text { candidates }\end{array}$ & $\begin{array}{l}\text { Growing university increasing research with faculty numbers increased by } \\
25 \% \text { over past three years }\end{array}$ \\
$\begin{array}{l}\text { Enthusiastic and committed to scholarship and tenure } \\
50 \% \text { with some publication experience }\end{array}$ & $\begin{array}{l}\text { Faculty Development Grants available (peer reviewed) } \\
\text { One course release time for research by application for up to } 2 \text { semesters } \\
\text { prior to tenure }\end{array}$ \\
SCHOOL & $\begin{array}{l}\text { Other PhD programs on campus and possibility for teams of research } \\
\text { COMMUNITY }\end{array}$ \\
Newly established PhD Program & $\begin{array}{l}\text { Large Healthcare Systems nearby: Large Institute for Research; Vice } \\
\text { President for Nursing Research } \\
\text { School's Alumni are key administrators in nearby HC facilities }\end{array}$ \\
Associate Dean for Research hired & Research and EBP Regional Committees with school faculty as members \\
Reasonable teaching load/ 18 credits an academic year \\
$\begin{array}{l}\text { Endowment funds targeted for faculty development } \\
\text { Graduate Assistantships in budget for faculty research } \\
\text { assistance }\end{array}$
\end{tabular}


Table 2. Summary of Major Strategies for the Domain of Discovery

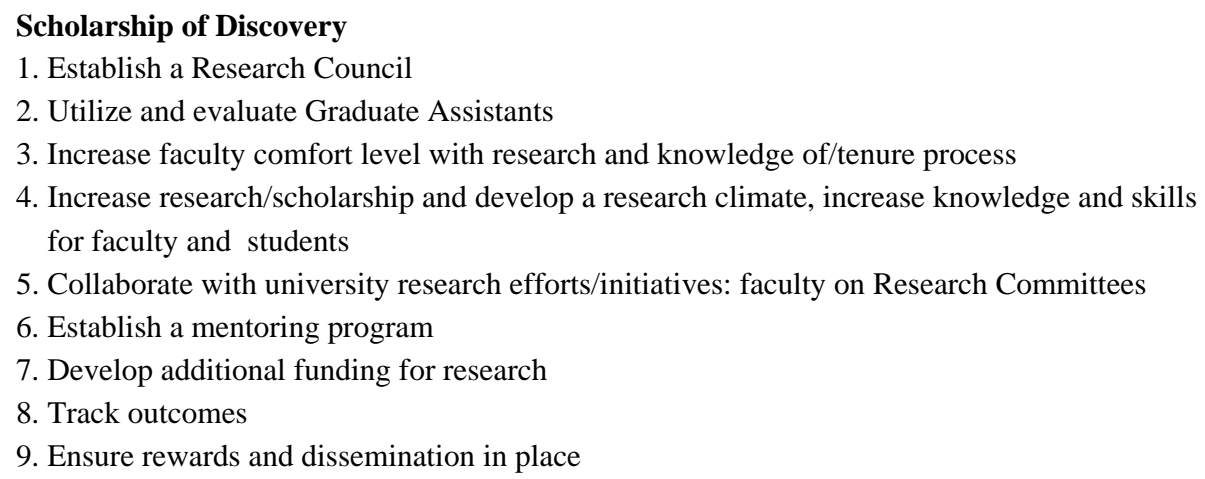

One of the most useful strategies was establishing a Research Council with the goals of establishing and maintaining a research climate and enhancing scholarly productivity. Members of the council met monthly to develop, implement, and evaluate research initiatives, collaborate and support faculty research endeavors, and ensure that faculty accomplishments related to scholarship were recognized. These activities included brown bag lunches for faculty research presentations, invited external experts, scholars and lecturers for research -related presentations and the "SON Research Days" for student poster presentations related to their research course requirements.

Individual faculty assistance was also a part of the domain of discovery. The Associate Dean for Research provided assistance with review of manuscripts for publication, conference abstracts and research proposals. Faculty membership on dissertation committees as well as doctoral student proposal review committees also added to the research climate and increased faculty research knowledge and skills.

The Mentoring Needs Surveys were reviewed by a committee to determine faculty needs and requests; protégés were matched with mentors for role development in the areas of teaching, service, or research. Each mentor agreed to set up specific time to meet with a protégé and establish an overall plan with specific goals. Mentors usually had 3-4 protégés.

An important aspect of sustaining a new research climate was in the form of rewarding and recognizing faculty accomplishments. Annual reports of faculty scholarship helped to track outcomes and gain recognition; publications and other forms of scholarship were announced in various venues - school bulletin boards, a research web page, and school/ university newsletters.

\subsection{Strategies to foster the scholarship of integration/ application}

The program also included activities to support faculty development in the scholarship of integration and application. To encourage interdisciplinary collaboration and synthesis of information within the university, faculty research programs from other schools were reviewed for topics that might lead to collaborative and team research and match some of our faculty members' interests. Meetings were established with several faculty from other schools and three "research teams" with members from the business and nursing schools proposed three collaborative research projects; two of these projects were awarded university "seed” money.

Collaboration with community clinical partners was accomplished through membership on a regional "Research and Evidence Based Practice” council. The School of Nursing Faculty served as resources for research efforts at several local hospitals and assisted with increasing nurses' knowledge related to evidence based practice through annual 'Research Days'. They were also involved in the planning of and participation in research conferences sponsored by clinical facilities. For further collaboration, two doctorally prepared nurses, one from a large healthcare system and one from a large local university were invited to serve as appointed Visiting Scholars to assist with teaching in our PhD program and 
to foster collaborative research. Recently, our Associate Dean for Research was appointed as a Visiting Scientist for nursing in one large healthcare system to further promote collaborative research. Another important outcome of our collaborative efforts is that one of our faculty members is now a co-principal-investigator with a doctorally-prepared nurse researcher at this healthcare system on a national study.

Boyer viewed service activities as a form of the scholarship of application if they were tied directly to a specialized field of knowledge. Within this framework, our faculty's work on university/ school committees was seen as a potential area for scholarship. As an example, faculty who were working on an extensive undergraduate curriculum revision on the school's curriculum committee had completed a comprehensive literature review as part of that process. They were encouraged to disseminate this work and eventually published both the literature review and an additional manuscript in peer reviewed journals on the process of curricular change.

\subsection{Strategies to foster the scholarship of teaching}

In addition to the teaching resources and activities already in place on campus which promote scholarly teaching, strategies were developed to support faculty who wished to develop the scholarship of teaching. Faculty who were interested in nursing education research were encouraged to apply for internal grants which provided "seed money" for pilot studies. Assistance from the office of the Associate Dean for Research was provided in the form of graduate assistants, statistical support, and review of manuscripts/presentations. The results of this work were successfully disseminated in both peer-reviewed publications and national presentations.

For example, building on their teaching-research connection, faculty published studies on techniques such as the effectiveness of podcasting in the classroom, the use of PDA technology in the clinical setting, and the outcomes/ best practices of simulation learning. Work that had been done to develop an innovative new curriculum was also published and presented nationally. Partnership with a local hospital to study the outcomes of an alternative clinical teaching model, the Dedicated Educational Unit (DEU) is also an ongoing integration of teaching and discovery.

\section{Outcomes/ results of the program}

Outcomes for the faculty development program were determined by assessing the achievement of the three program goals. The program goal of increasing faculty scholarship was measured by the number of presentations, publications and funded projects for the faculty in the school over a five year period; Figure 1 presents these data. Data were reviewed annually during the project's implementation phase with some adjustments made based on outcomes. For example, some faculty were presenting posters locally rather than nationally and we made suggestions to increase funding for presentations at national conferences. We noted that part of this was anxiety regarding a "national" audience; we observed that preparatory activities such as faculty presentations at brown bag lunches helped to increase national presentations.

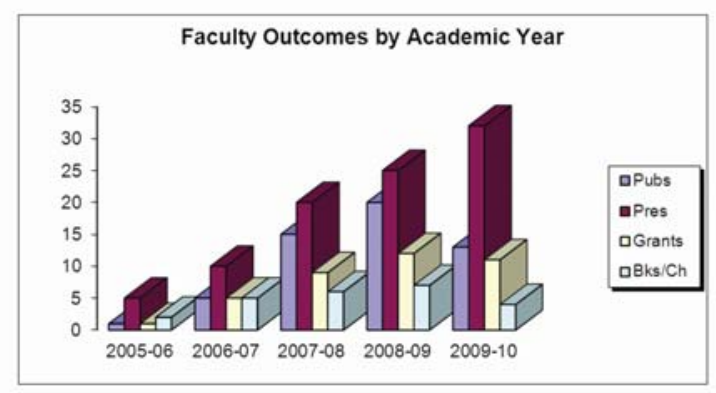

Figure 1. Outcomes for Scholarship of Discovery 
A second program goal was to create and maintain a robust research environment in the school. The research culture is evident by the numerous ongoing discovery-related activities in the school mentioned earlier such as faculty presentations, invited lectures, workshops, and by the increase in student participation in research activities related to their course work.

Success regarding the goal of an increase in the school's visibility was primarily measured by the number of presentations at national meetings and the increase in publications but also by the increase in research collaboration on campus, locally with clinical partners, and on one national study. Figure 1 shows all newly funded projects for a specific year; all but two of these are internal funds for pilot studies. Further enhancing the school's visibility, our faculty also serves as peer reviewers for journals and for abstracts for national conferences.

Faculty work related to the scholarship of integration and application continues and three established interdisciplinary research teams are in various stages of the research process. Related to integrating teaching and service, faculty now seek out work on specific committees that could be integrated with teaching and discovery such as faculty with technology expertise serving on committees dedicated to campus and teaching technology. The community collaboration that began as committee membership has grown into at least two collaborative research projects and has resulted in presentations and two manuscripts that are in the development or review stage.

The most influential strategy for outcomes was the development of a research council. This was pivotal in changing the culture and it served as the planning arm for many of the development activities such as visiting lectureships, brown bag faculty luncheons to share research findings, and student scholarship and research days to showcase the work of students across all levels.

\section{Discussion}

Boyer's model was as an effective framework to assess resources, plan development activities, and evaluate outcomes across all areas of faculty scholarship. As every university has its own unique faculty development needs, the model provided a guide to develop targeted strategies which addressed specific areas. A lack of resources has been identified as a challenge to faculty development in the literature ${ }^{[27]}$. The systematic assessment of resources needed for faculty success in each of Boyer's domains was instrumental in planning the program, and assisted us with determining needs.

Reasons for our successful faculty scholarly productivity and satisfaction are multifactorial and include factors such as feeling supported by administration and peers and having adequate time for scholarship ${ }^{[8]}$. In this program, faculty identified strategies such as individual assistance with manuscript preparation, providing a timeline for completion, and the availability of research assistants for data entry and library research as significantly assisting them in attaining their goals. Table 3 provides feedback from a mentee regarding her experience during five years of pre-tenure work.

Table 3. One Mentee’s Perspective

\footnotetext{
- "Mentoring support and feedback helped me to develop an identity as a scholar"

- "Program allowed for involvement in a mentor’s projects/ assisted with tenure materials"

- "Informal peer mentoring was encouraged with peer collaboration on publications"

- “Goals were individualized to my needs- I already felt comfortable with teaching/ service expectations. Needed support with publications and scholarship area”

- "Culture of research created within a supportive environment”.

- " "Publication of my dissertation was an important first step which I may not have pursued on my own without support.”

- "Encouraged a faculty team approach to scholarship to increase scholarly productivity."
}

Creating a research environment has also been shown to be an effective way of encouraging scholarship ${ }^{[32]}$. Pratt's characteristics for changing a culture were specifically helpful for the goal of creating a robust research climate in the 
school. The establishment of a Research Council, a standing committee in the school, was an essential aspect of the faculty development program. Research activities sponsored by the Council such as faculty brown bag presentations and workshops helped to promote a research culture in the school. Rewards in the form of conference funding, reports on faculty scholarship, a sense of collegiality and knowledge of administrative support enhanced the culture ${ }^{\text {[2] }}$. These dissemination activities also increased the program goal of enhancing the school's visibility.

There were three major drawbacks in developing and maintaining this program. First, as noted in the literature, socializing into a faculty role should start with an orientation to the responsibilities of the role ${ }^{[6]}$. However, an organized formal faculty orientation program was not in place in the school. This is being addressed now with a formal day -long orientation program; its effectiveness will be evaluated with a faculty survey.

Second, the mentoring program with plans for ongoing relationships between mentors and protégés was not a lasting one. At about six-nine months, only one or two novice faculty members were continuing to meet with mentors and this was primarily around developing a research program. This was not formally evaluated, but a lack of available time on the part of the protégés was often cited as a reason for discontinuing meetings. A built in evaluation plan for the mentoring program process would have provided the information needed regarding program failure and the specific barriers, difficulties, and time constraints. Having protégés and mentors matched according to available time for this work would also have been helpful ${ }^{[6]}$.

\section{Conclusion}

Faculty development programs should be tailored to the type of university in which nursing faculty are employed and help to achieve the mission and goals of the institution. Some programs use Boyer as a model for interpreting scholarship; building a faculty development program using this model is essential. Often the types of scholarship are integrated; for many nursing faculty members, this can provide a much needed program of research in which accomplishments in one aspect of scholarship such as teaching can influence the scholarship of discovery. For example, curriculum development and program evaluation that some faculty had undertaken, viewed as part of the teaching role, became the basis for the scholarship of discovery and influenced publications and internally funded research projects.

To be successful, comprehensive faculty development programs must have an organized step by step plan, administrative support, adequate resources for the scholarship of discovery, reasonable teaching loads, and an enthusiastic and committed faculty. Ongoing evaluation of both the outcomes and the process is essential.

\section{References}

[1] Wilson R. A higher bar for earning tenure. Chron High Educ. 2001; 47: A12.

[2] Boyer E. Scholarship reconsidered: Priorities of the professoriate. Princeton: Carnegie Institute for the Advancement of Teaching; 1990.

[3] Fitzpatrick J, McCarthy G. Boyer and scholarship revisited. Appl Nurs Res. 2010; 23: 121. PMid:20643320 http://dx.doi.org/10.1016/j.apnr.2010.04.001

[4] American Association of Colleges of Nursing. Fact sheet: Nursing shortage [Internet]. 2010. Available from: http://www.aacn.nche.edu/media/FactSheets/NursingShortage.htm.

[5] Reinhard SC, Hassmiller SB. Partners in solution to the nurse faculty shortage. J Prof Nurs. 2011; 27: 197-201. PMid:21767816 http://dx.doi.org/10.1016/j.profnurs.2011.04.003

[6] National League for Nursing. Position statement on mentoring of faculty. New York, NY: 2006.

[7] Benner P, Sutphen M, Leonard V, Day L. Educating nurses: a call for radical transformation. NY: Jossey Bass, 2010.

[8] Durham-Taylor J, Lynn CW, Moore P, McDaniel S, Walker J. What goes around comes around: improving faculty retention through effective mentoring. J Prof Nurse. 2008; 24: 337-346. PMid:19022206 http://dx.doi.org/10.1016/j.profnurs.2007.10.013

[9] Hessler K, Richie H. Recruitment and retention of novice faculty. J Nurs Educ. 2006; 45: 150-154. PMid:16722496 
[10] Lewallen LP, Crane P, Letvak S, Jones E, Hu J. An innovative strategy to enhance new faculty success. Nurs Educ Perspect. 2003; 24: 257-260. PMid:14535147

[11] Gaza E, Shellenbarger T. Successful enculturation: strategies for retaining newly hired faculty. Nurse Educ. 2005; 30: 251-254. PMid:16292147

[12] Records K, Emerson R. Mentoring for research skill development. J Nurs Educ. 2003; 42: 553-557. PMid:14694996

[13] Savage H, Karp R, Logue R. Faculty mentorship at colleges and universities. College Teaching. 2004; 52: 21-24. http://dx.doi.org/10.3200/CTCH.52.1.21-24

[14] Blauvelt M, Spath M. Passing the torch: a faculty mentoring program at one school of nursing. Nurs Educ Perspect. 2008; 29: 29-34. PMid:18330419

[15] National League for Nursing. Mentoring of nurse faculty toolkit. New York, NY: NLN; 2008.

[16] Allison-Jones LL, Hirt JA. Comparing the teaching effectiveness of part-time and full-time clinical nurse faculty. Nurs Educ Perspect. 2004; 25: 238-244. PMid:15508563

[17] Felton G. Perspectives of faculty development. J Contin Educ Nurs. 2000; 31: 83-87. PMid:11051959

[18] Bartels J. Preparing nursing faculty for baccalaureate-level and graduate-level nursing programs: role preparation for the academy. J Nurs Educ. 2007; 46: 154-158. PMid:17474484

[19] Storch J, Gamroth L. Scholarship revisited: A collaborative nursing education program’s journey. J Nurs Educ. 2002 ; 41 : $524-531$. PMid:12530564

[20] Byrne M, Keefe M. A mentored experience in maternal-infant research. J Prof Nurse. 2003; 19: 66-75. PMid:12748931 http://dx.doi.org/10.1353/sof.2001.0029

[21] Hawranik P, Thorpe KM. Helping faculty enhance scholarship. The J Contin Educ Nurs. 2008; 39: 155-163. http://dx.doi.org/10.3928/00220124- 20080401-02

[22] Matthew-Maich N, Mines C, Lunyk-Child O, Carpio B, Drummond-Young M, Noesgaad C, Linton J. Evolving as Nurse Educs in problem-based learning through a community of faculty development. J Prof Nurse. 2007; 23: 75-82. PMid:17383599 http://dx.doi.org/10.1016/j.profnurs.2006.07.004

[23] Raff B, Arnold J. Faculty development: an approach to scholarship. Nurse Educ. 2001; 26:159-161. PMid:16372641 http://dx.doi.org/10.1097/00006223-200107000-00008

[24] Shaffer SC, Lackey SP, Bolling, GW. Blogging as a venue for nurse-faculty development. Nurs Educ Perspect. 2006; 27: 126-128.

[25] Smith J, Zsohar H. Essentials of neophyte mentorship in relation to the faculty shortage. J Nurs Educ. 2007; 46: 184-186. PMid:17474489

[26] James K. Bridging the gap: Creating faculty development opportunities at a large medical center. The J Contin Educ Nurs. 2004; 35: 24-27. PMid:14870907

[27] Foley BJ, Redman RW, Horn EV, Davis GT, Neal EM, Van Riper M.L. Determining nursing faculty development needs. Nurs Outlook. 2003; 51: 227-232. http://dx.doi.org/10.1016/S0029-6554(03)00159-3

[28] Smesny A, Williams J, Brazeau G, Weber R, Matthews H, Das S. Barriers to scholarship in dentistry, medicine, nursing \& pharmacy practice faculty. Am J Pharm Educ. 2007; 71: 1-9. PMid:17429501

[29] Allen M, Field P. Scholarly teaching and scholarship of teaching: noting the difference. Int J Nurs Educ Scholarsh [Internet]. 2005; 6: Article 27. Available from: http://www.bepress.com/ijnes/vol2/iss1/art

[30] Richlin L. Scholarly teaching and the scholarship of teaching. New Directions for Teaching and Learning. 2001 ; 86: 57-67. http://dx.doi.org/10.1002/tl.16

[31] Atkinson M. Reconceptualizing scholarship and transforming the academy. Social Forces. 2001; 79: 1217-1229. http://dx.doi.org/10.1353/sof.2001.0029

[32] Pratt M, Margaritis D, Coy D. Developing a research culture in a university faculty. J Higher Educ Pol Manage. 1999 ; $21: 43-55$. http://dx.doi.org/10.1080/1360080990210104 